\title{
A comparison \\ of on-site efificiency tests on a reversible pump-turbine using the radioisotope constant-rate-injection and current-meter methods of flow measurement
}

\author{
by G.V. Evans \\ Harwell Flow Measurement Service, \\ Atomic Energy Research Establishment, \\ Harwell U.K.
}

\author{
J.J. Aspurll \\ Department \\ of Civil Engineering (Hydrology) \\ Iberduero S.A., Bilbao (Spain)
}

\author{
and A. Bassy \\ Saltos del Sil, \\ S.A.
}

Madrid (Spain)
1 INTRODUCTION.

2 Description of the SANTIAgo del Jares hydro-electric scheml.

3 DESCRIPTION OF EFFICIENCY TESTS USING CURRENT-METERS TO MEASURE WATER FLOWRATES.

3.1 Measurement of water flowrates.

3.2 Measurement of pressure head.

3.3 Measurement of electrical power.

3.4 Measurements of differential pressure and guide-vane opening.

4 THE RADIOISOTOPE CONSTANT-RATE-INJECTION METHOD.

4.1 Principles of the method.

4.2 Mixing distance considerations.

4.3 Choice of isotope.
5 DESCRIPTION OF EFFICIENCY TESTS USING THE RADIOISOTOPF CONSTANT-RATE-INJECTION METHOD TO MEASURE WATER FLOWRATES. 5.1 Measurement of water flowrates.

5.1.1 Supply of isotope.

5.1 .2 Injection.

5.1 .3 Sampling.

5.1.4 Counting.

5.1.5 Dilution.

5.2 Measurement of pressure head.

5.3 Measurement of electrical power.

5.4 Measurements of differential pressure and guide-vane opening.

6 Test Results.

7 Conclusions.

8 ACKNOWLEDGEMENTS.

9 References.

\section{1 - Introduction}

The selection of large hydraulic machines, such as mixed-flow or centrifugal pumps used in cooling water systems of thermal power stations, or reversible pumpturbines used in pumped storage hydro-electric schemes, is generally based on hydraulic tests of small-scale models of the machines. The efficiency and optimum operating flowrate of the prototype machine are generally determined by the application of 'scaling laws' to the results of the model tests with no actual testing of the prototype after installation. Scepticism of the value of on-site tests of machines has been due mainly to uncertainties in the measurements and to the cost and inconvenience of the tests.
The largest uncertainty associated with on-site tests is considered to be in the measurement of water flowrate and considerable effort has been expended in the development of accurate and convenient methods of measuring large flowrates of water during on-site tests.

A number of methods, based on widely different physical principles of measurement (i.e. velocity, momentum transfer and mass diffusion) were developed for this application and an International Test Code [1] incorporating these methods, was drafted to guide test engineers in obtaining satisfactory accuracies of measurement. However, the accuracies generally quoted for these methods were not obtained from objective assessments of the measurements and comparative tests at Kinlochleven [2], Fätschbach [3] and Finlarig [4] 
hydro-electric stations, in which various methods of flow measurement were used, showed differences in measurement considerably greater than the individual tolerances "claimed' by the exponents of the various methods.

More recent developments of a dilution method, in which a radioisotope tracer is injected continuously into the flow, has resulted in a method of flow measurement which is amenable to an objective analysis of the overall error of measurement $[5,6]$. The analysis of error in this method, the radioisotope constant-rate-injection method, has been verified in flow test systems by comparison with a gravimetric method of measurement and has been used to assess the errors obtained for approximately 300 flowrate measurements carried out over a five year period [7]. This analysis showed that a mean error of $\pm 0.6 \%(95 \%$ confidence level) was obtained and that errors exceeding $\pm 1 \%$ were extremely unlikely.

To obtain some "external" verification of this error analysis as applied to the measurement of large flowrates of water and to demonstrate further the practical advantages of using the method during on-site testing of hydraulic machines, measurements were made of water flowrates during efficiency tests on a reversible Francis-type pumpturbine at Santiago del Jares in Spain. These tests were carried out in June 1972 for Saltos del Sil SA and the measurements obtained were compared with simultaneous measurements derived from flowrate indicators' calibrated during previous tests, in July 1970 , in which the flowrates were measured by the use of propeller current-meters. In addition the values of efficiencies of the pump-turbine derived from the tests were compared directly with the values obtained from the previous current-meter tests.

\section{2 - Description of the Santiago del Jares hydro-electric scheme}

The Santiago del Jares hydro-electric scheme consists of the Central del Jares power station containing four hydraulic turbines. Two Kaplan-type turbines are supplied with a flow of water from the river Sil. Two Francis-type reversible pump-turbines are supplied with water from the river Jares during electrical generation and also deliver water from the river Sil to the river Jares at the Santa Eulalia dam during pumping operation.

When the reversible pump-turbines are operated in the turbine direction, water is supplied from the river Jares through the pressure gallery, to a surge chamber and penstock. The penstock, which varies in diameter from 3.0 to 2.6 metres, is approximately 560 metres long and bifurcates into 2 pipes of 1.6 metres diameter at a distance of approximately 10 metres upstream of the machines. The drafttubes of the machines combine to form a common tailrace tunnel of approximately 4 metres diameter which discharges into the river Sil.

The main features of the pumped-storage system are shown in Figs. $1 a$ and $1 b$ and have the following characteristics:

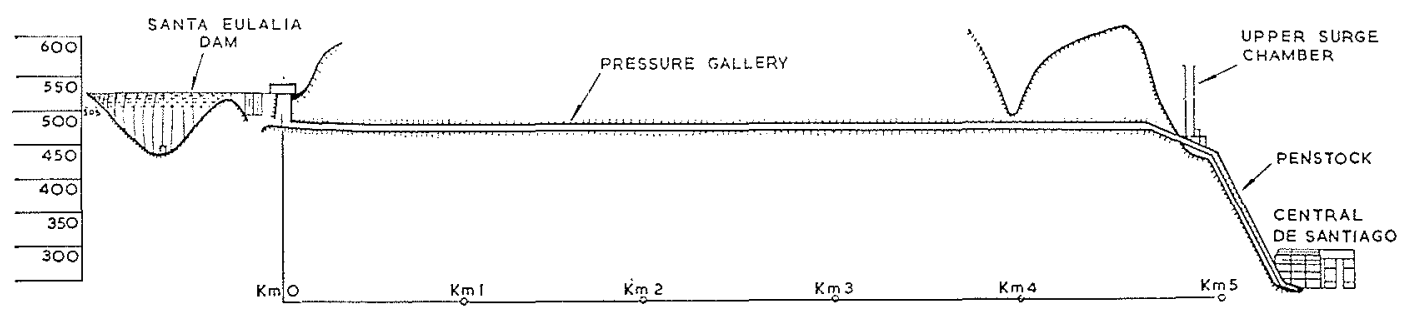

1.a/ Diagran of Santiago del Jares pumped-storage scheme.

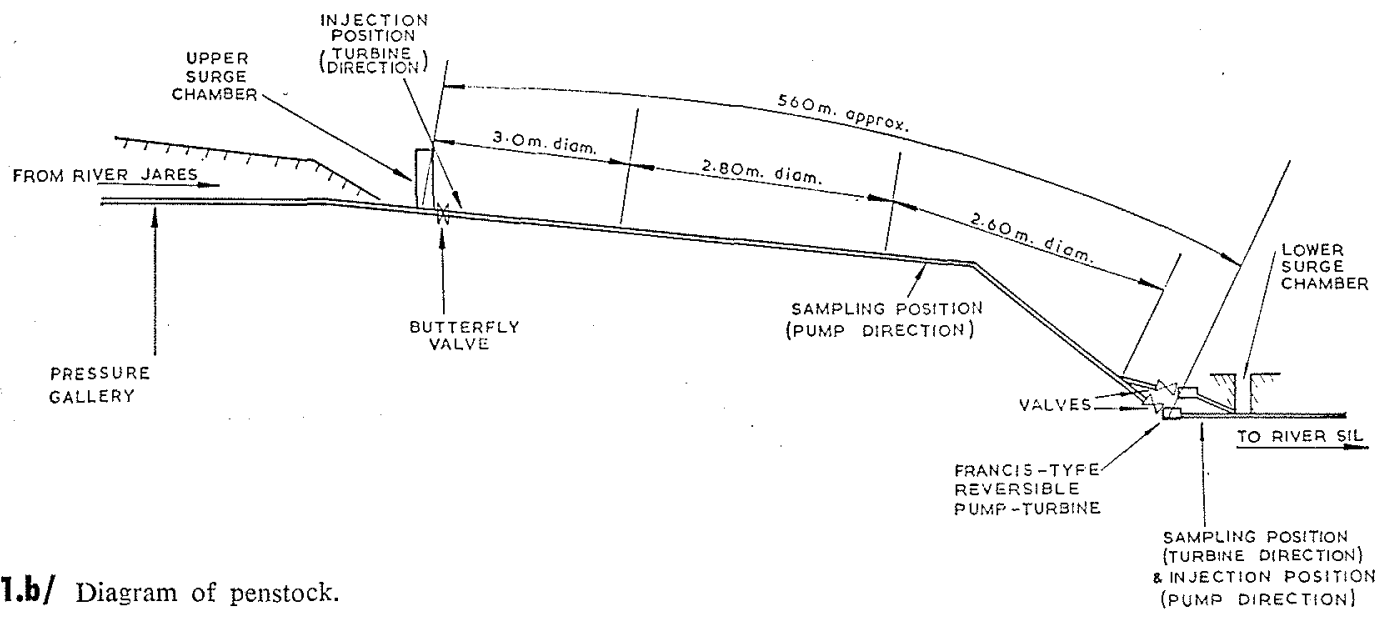


HYDRAULIC SYSTEM:

Volume of dam basin ..........

Useful capacity of dam basin ......

Maximum working level of water in basin $\ldots \ldots \ldots \ldots \ldots \ldots \ldots$

Minimum working level of water in

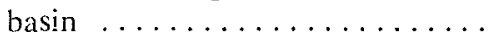

Accumulated energy .............

inth of pressure gallery

Diameter of pressure gallery .... $3.0 \mathrm{~m}$

Maximum water flow through gallery ............. $28.0 \mathrm{~m} 3 / \mathrm{s}$

\section{Hydraulic MACHINES:}

Type : Vertical shaft, Francis-type reversible pump-turbine.

No.

\section{TURBINE:}

Power output $\ldots \ldots \ldots \ldots \ldots \ldots$ 26.610 MW

Max. flow ......................... $14 \mathrm{~m}^{3} / \mathrm{s}$

Net head $\ldots \ldots \ldots \ldots \ldots \ldots \ldots 216.5 \mathrm{~m}$

Pump:

Generated head ........... $241 \mathrm{~m}$

Power input ............. 24.095 MW

Flowrate $\ldots \ldots \ldots \ldots \ldots \ldots \ldots . \ldots . \ldots \ldots \mathrm{m}^{3} / \mathrm{s}$

Speed ............... 500 R.P.M
Speed $\ldots \ldots \ldots \ldots \ldots \ldots \ldots \ldots \ldots$ 500 R.P.M.

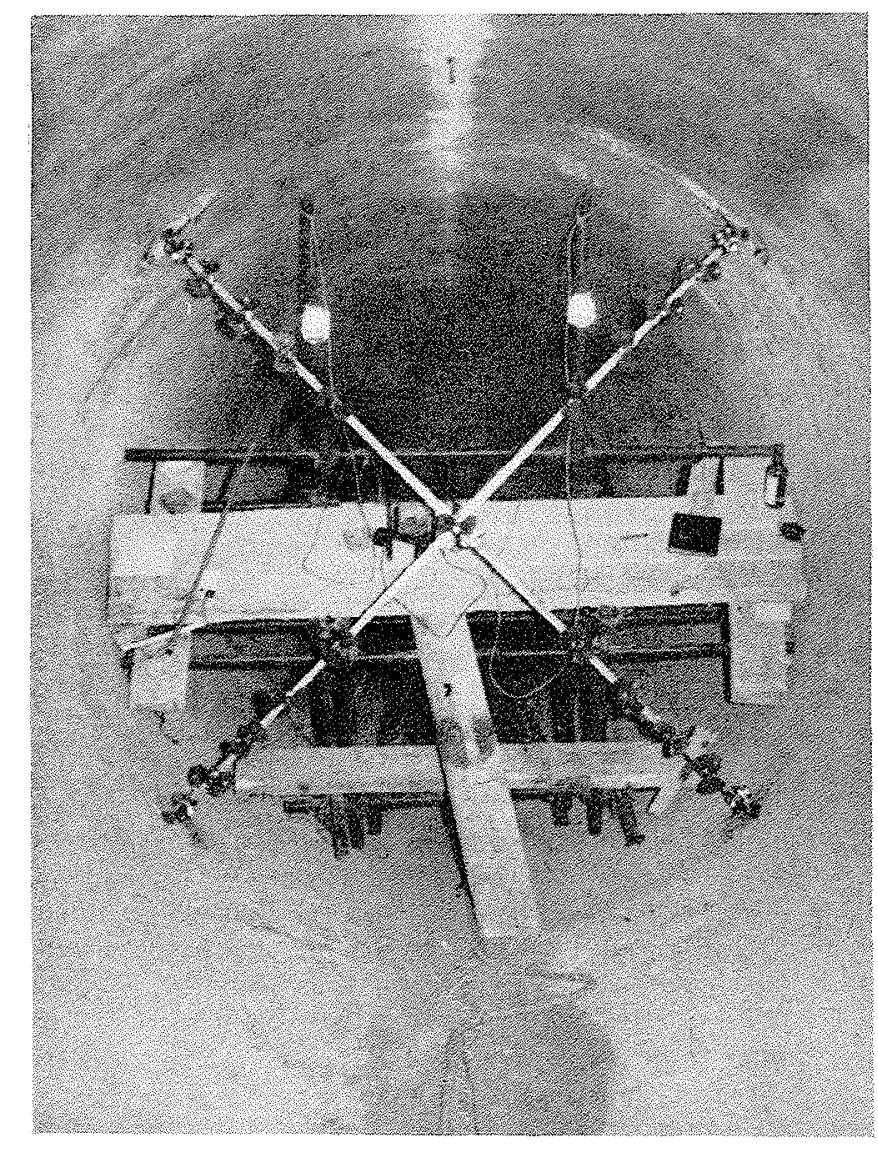

\section{3 - Description of efficiency tests using current-meters to measure water flowrates}

The efficiency tests were carried out on one of the reversible pump-turbines by the Civil Engineering Division (Hydrology) of Iberduero SA, Bilbao, in July 1970. During tests, measurements were also made of the angles of opening of the guide vanes and of pressure differences occurring within the volute and draft-tube of the machine to enable these measurements to be used to indicate flowrate during routine operation of the power station.

A total of 12 measurements of efficiency were made over the complete operating range of the pump-turbine; 9 with the machine operating as a turbine and 3 as a pump. Satisfactory 'calibration' of the flow measurement indicators was also obtained during the tests.

\section{1 - Measurement of water flowrates}

The flowrates of water were measured using currentmeters $(a)$ installed in the penstock between the upper surge chamber and the pump-turbine. The current-meters were positioned approximately in the middle of a straight length of conduit of 33 conduit diameters. Although the

(a) Manufactured by A. Ott, Kempten, Bayern (W. Germany).

2/ Location of current-meters for water flow measurements

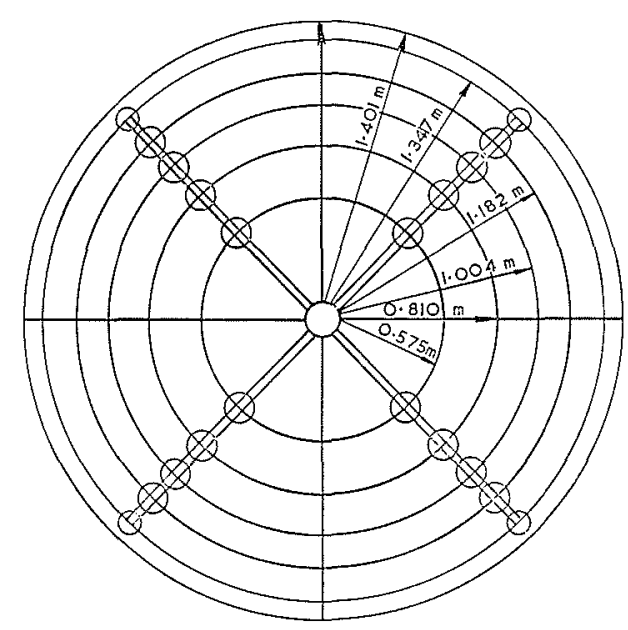


position of the measurement section did not conform exactly to recommendations of the International Code for field acceptance tests of hydraulic turbines which states minimum distances of 20 and 5 conduit diameters upstream and downstream of the meters respectively, it was chosen as the best available position in the flow system for testing the machine both as a turbine and as a pump.

The current-meters were positioned on four radial arms constructed to form a cross in the pipe cross-section. A total of 21 current-meters was used in the configuration shown in Fig. 2 which complies with the recommendations given in the International Code.

The rotor blades of all the current-meters had a helical pitch of $0.25 \mathrm{~m}$ and an outside tip diameter of $125 \mathrm{~mm}$ except for the outer current-meters which were of $80 \mathrm{~mm}$ diameter to allow closer positioning $(\simeq 54 \mathrm{~mm}$ ) to the wall of the conduit, thus reducing the degree of extrapolation required to determine the velocity distribution in the outer periphery of the conduit.

The water velocities in the peripheral zone between the outer current-meters and the conduit wall were calculated from the expression:

$$
V=V_{0}\left[1-\left(r^{2} / R^{2}\right)\right]^{1 / m}
$$

where $V_{0}$ is the velocity at the centre of the conduit. The value of the exponent $1 / m$ was determined from the mean relationship of relative velocity with radius obtained from each set of current-meters, for all the tests carried out. This analysis was found to give a value of $m=8$.

The area of the conduit at the measurement section was determined from the mean value of measurements of 16 radii. Measurements were made to within $0.5 \mathrm{~mm}$ on a radius of $1.4 \mathrm{~m}$.

The flowrates were calculated by integrating the velocity curves by planimetry and graphical methods. As recommended in the International Code, both the relationships of velocity $V$ against the square of the radius $R^{2}$ and $V R$ against $R$ were examined and found to give agreement to within $0.15 \%$ which is well within the acceptable level of the International Code.

\section{2 - Measurement of pressure head}

The net pressure head across the machines was determined by pressure measurements using a Neyrpic dead weight manometer for the high-pressure side of the machine and a column of mercury for the low-pressure side. Allowance was made for the difference in potential head between the two measurement positions, the velocity heads and any pressure loss due to friction occurring between the machine and the measurement positions (Fig. 3).

\section{3 - Measurement of electrical power}

The electrical power generated by the turbine and supplied to the pump was measured by means of the "three watt-meter method". The instrumentation used, which was independent of the normal measurement system of the power station, consisted of transformers (precision class 0.2 ), connected between the terminals of the electrical machine and three meters; one Landis-Gyr standard kilowatt-hour meter and two Galileo watt-meters (precision class 0.2 ).

Subsidiary measurements of excitation current and voltage and the temperature of the field windings were made to allow for losses in the electrical machine. Hence the power from or to the hydraulic machine could be determined.

\section{4 - Measurements of differential pressure and guide- vane opening}

During each measurement of flowrate, supplementary measurements were made of differential pressures arising within the volume or draft-tube of the machine and of the degree of opening of the guide vanes, so that these measurements could be used on subsequent occasions to indicate the flowrate of water passing through the machine.

The positions of the pressure-tapping points for the turbine and pump tests are shown in Figs. $4 a$ and $4 b$ respectively. Pressure differentials were measured with a Bopp and Reuther water/mercury manometer.

The degree of opening of the guide vanes was measured directly on a 'scale' laid in the rim of the guide ring.

\section{4-The radioisotope constant-rate-injection method}

\section{1 - Principles of the method}

Measurement of flow by the constant-rate-injection method is based on a comparison between the concentration $C_{1}$ of a tracer continuously introduced at a known rate $q$ with the concentration $C_{2}$ of samples removed from some position beyond the mixing distance.

If $C_{0}$ is the initial concentration of the fluid flowing at a rate $Q$, then it can be shown that,

$$
Q=q\left(C_{1}-C_{2}\right) /\left(C_{2}-C_{0}\right)
$$

Generally $C_{1} \gg C_{2}$ and $C_{2} \gg C_{0}$, so that equation (1) reduces to,

$$
Q=q C_{1} / C_{2}
$$

For a known injection rate, $Q$ can thus be determined simply by comparing the concentration of the injected solution with the concentration of samples removed from the conduit. Provided the flow is turbulent, the method is completely independent of the velocity of the fluid, the dimensions of the conduit, or variations in these dimensions should they occur. The presence of hydraulic machines does not affect the result and in fact may help to increase the accuracy of measurement by increasing the degree of mixing of the tracer in the fluid beyond that due to the method of injection and to turbulent dispersion during transit.

Because the measurement of $q, C_{1}$ and $C_{2}$ can be made independently of the hydraulic system, a complete analysis of the magnitude of the errors associated with the measu- 
rement of flow is possible. This is one of the most important characteristics of this method of flow measurement [5].

In practice, the injected solution is introduced for a period which is sufficiently long to establish a region of uniform concentration at the sampling point and to enable the required number of samples to be withdrawn. In the present tests, an injection period of about $15 \mathrm{~min}$. was used and about 20 samples were extracted at each flowrate.

\section{2 - Mixing distance considerations}

In order to guarantee an accurate measurement when using the constant-rate-injection method, it is essential that the tracer is completely mixed before samples are extracted for measurement. Consequently, as mixed-flow pumps have previously been shown to induce appreciable mixing [8], the pump-turbine was included in the flow system between the injection and sampling positions in order to supplement mixing due to turbulent dispersion during transit of tracer in the conduit.

When the machine was operated as a turbine, injection was made through a tapping in the pipe wall at the base of the surge chamber and samples were withdrawn through 4 tapping points equally spaced around the circumference of the draft tube at a distance of about 10 metres downstream of the machines. The injection and sampling points were separated by a distance equivalent to about 200 pipe diameters including the pump-turbine.

When the machine was operated as a pump, the tracer was injected through the same tappings used for sampling during the turbine tests. Samples were extracted from 4 tappings equally spaced around the pipe at about 190 metres downstream of the machine. Mixing was achieved by the combined effect of a multipoint injection

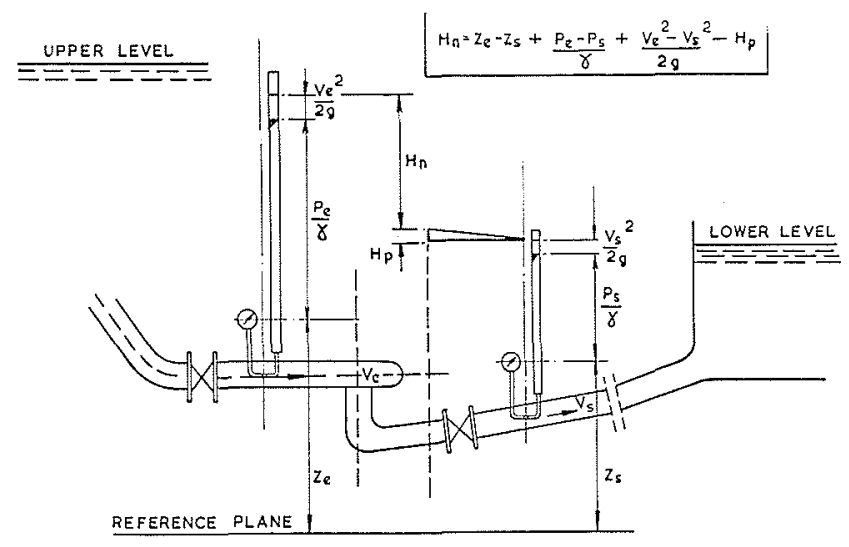

3.a/ Development of net pressure head across turbine.

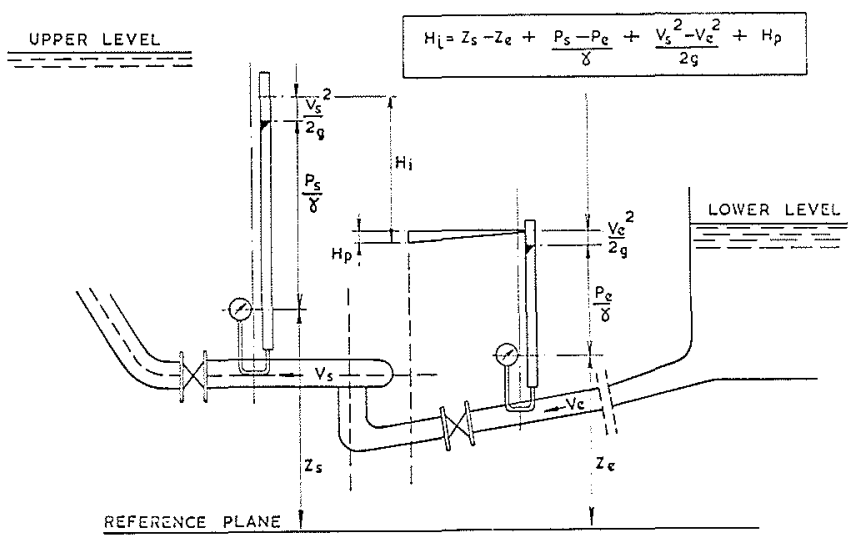

3.b/ Development of net pressure head across pump.

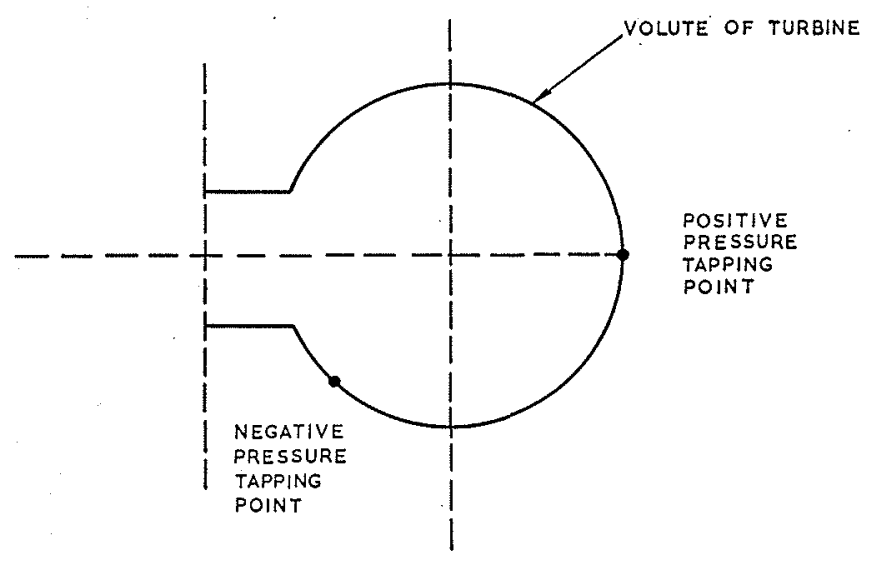

4.a/ Position of pressure tapping points used to indicate flowrate during turbine tests.

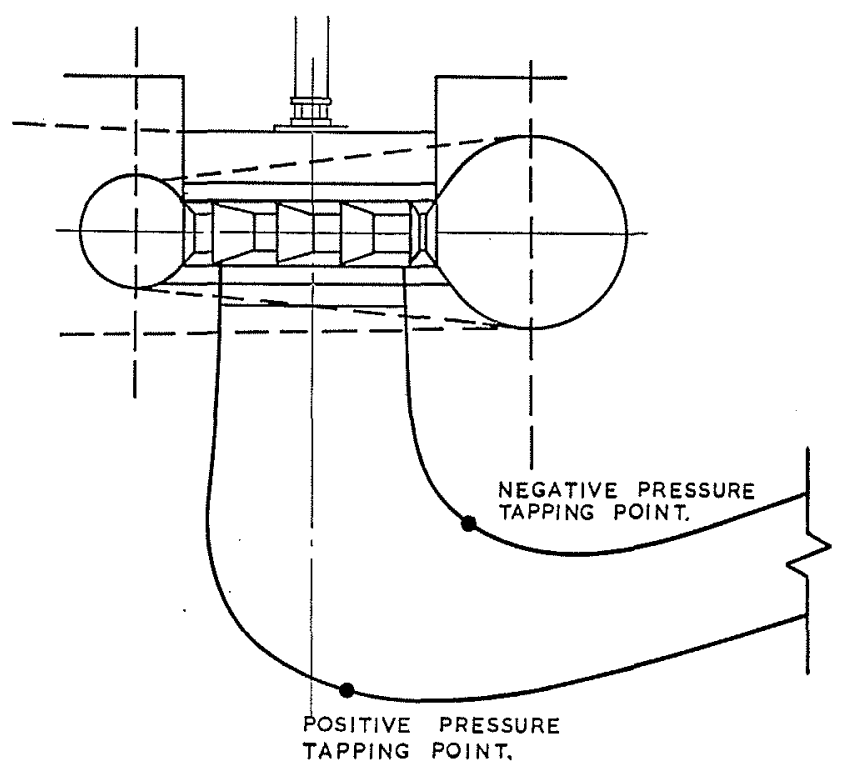

4.b/ Position of pressure tapping points used to indicate flowrate during pump tests. 
arrangement, the mixing induced by the hydraulic machine itself and the turbulent dispersion in about 80 diameters of conduit. In addition, the multipoint sampling system tended to average any residual variations in concentration at the sampling region.

From previous experience, it was considered that this system ensured adequate mixing of the tracer. Any variations in concentration existing at the sampling point would be observed from the measurements of concentration from all the samples taken during a test and result in an increased estimated error derived for the flow measurement.

\section{3 - Choice of isotope}

The isotope used in these tests was bromine 82 in the form of a dilute solution of potassium bromide. This tracer, which has been used frequently for the measurement of water flow, does not adsorb on the surfaces of metal or concrete pipes or on any suspended particles of silt which may be present in the flow.

The half-life of bromine 82 is 35.9 hours but as the irradiation of potassium bromide also produces some potassium 42, with a half-life of 12.45 hours, the half-life of the material used was measured over the period of the tests. A delay of two days between the irradiation and use of the potassium bromide was introduced to allow the radioactivity from the potassium to decay to a low level

\section{5 - Description of efficiency tests using the radioisotope constant-rate-injection method to measure water flowrates}

These tests were carried out in June 1972 by a joint team of the Flow Measurement Service of the Atomic Energy Research Establishment, Harwell, England and the Civil Engineering Division (Hydrology) of Iberduero SA: Bilbao; the Harwell personnel being responsible for carrying out the flow measurements by the radioisotope constant-rateinjection method.

A total of 11 separate flowrates were measured over a period of 3 days; 8 of these measurements being made with the machine operating as a turbine. The measurements of flow in the turbine direction were made before the measurements in the pump direction to prevent recirculation of the tracer.

During these tests the flowrates were also determined indirectly from the measurements of power, the opening of the guide vanes and from the pressure differences across the 'scroll' of the turbine (Winter-Kennedy method) as calibrated in the previous current-meter tests.

\section{I - Measurement of water flowrates}

\subsection{1 - SUPPLY OF ISOTOPE}

The isotope was supplied as potassium bromide crystals by the Junta de Energia Nuclear (J.E.N.), Madrid, and was delivered to site, one day before the start of the tests, in aluminium irradiation cans (A cans) stored in leadshielded transport containers. A total of 11 curies of radioactivity was used for all the tests over the 3 day period which resulted in approximately 1.7 curies being injected into the flow system on each day of tests.

This corresponded to a concentration of radioactivity in the water immediately before discharge from the power station of approximately $5 \times 10^{-5} \mu \mathrm{Ci} / \mathrm{ml}$ which is about 5 times less than the allowed maximum concentration of bromine 82 in drinking water. Further dilution occurred by mixing with the water in the river Sil and the river Jares.

\section{$5.1 .2-$ INJECTION}

At the beginning of each day of tests, an aqueous solution of potassium bromide was prepared on site by dispensing an amount of crystals from the A-can into a stainless steel breaker and dissolving the crystals in warm water. This solution was transferred to an aspirator and diluted with water to a total volume of 4 litres, which was sufficient to enable 4 separate flow measurements to be made in one day. Uniform concentration of radioactivity within the solution in the aspirator was achieved by agitating the liquid for several minutes after the tablets had dissolved, by blowing air through a multi-orifice injector immersed in the solution. Samples of the solution were taken and retained until the radioactivity had decayed to a safe level. The density of these samples was then measured to enable the mass injection rate of the pump to be determined.

The aspirator, which was mounted inside a lead shield, was permanently coupled to an injection pump which was essentially a constant-speed, single-stroke piston operating in an accurately-machined cylinder. The tracer solution was introduced into the flow system by injecting into a secondary flow of water which was pumped into the conduit.

For the tests with the machine operating as a turbine, the secondary circuit was obtained by pumping water from two steel drums of approximately $2.0 \mathrm{~m}^{3}$ capacity into the conduit at a rate of about 11 litres/min. by means of a high-pressure pump ${ }^{(b)}$. Tracer was injected through a stainless steel capillary tube $(\simeq 1 \mathrm{~mm}$ bore $)$ into the inlet side of the pump. The injection arrangement is shown in Fig. 5 a.

The injection pump was filled simply by withdrawing the piston, after which the tap connecting the pump to the aspirator was closed and a tap in the supply to the secondary circuit was opened: the pump was then ready to inject.

As the injection pump is powered by a synchronous motor and the calibrated injection rate is referred to $50 \mathrm{~Hz}$, the average frequency of the electrical supply over the injection period was measured to enable the required correction to be made to the injection rate. This was done by counting the number of cycles obtained over accurately measured periods during the period of injection. These periods were measured by means of a crystal-controlled oscillator to an accuracy of better than 1 in $10^{5}$.

(b) "Mono" pump (type D. 26) with a maximum operating pressure of $2,750 \mathrm{kN} / \mathrm{m}^{2}$. 

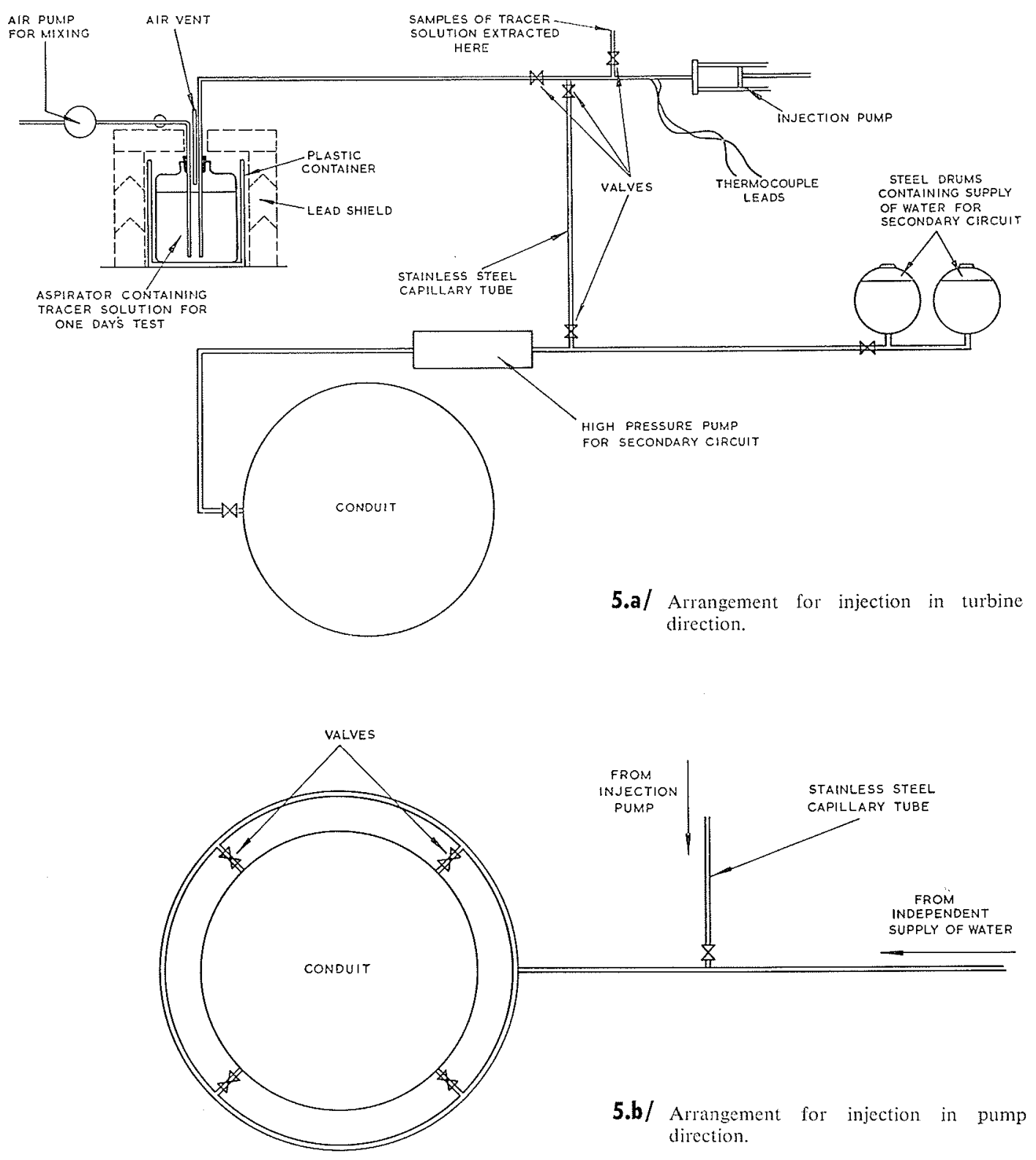

\section{1 .3 - SAMPLING}

At the sampling points, water was withdrawn from the conduit through existing connections in the wall of the conduit. The water flowed through a re-entrant vessel in which was located a scintillation detector connected to a countrate meter and a pen recorder and a proportion of the flow was diverted into sample bottles by means of a "sampling-gun", the operation of which was arranged to mark the start of each sampling period on the recorder chart. A diagram of the system is shown in Fig. 6. By observing the reading on the recorder it was possible to ensure, within the limits of visual observation of the chart trace, that samples were taken only during a period of constant concentration at the sampling point. The period of each test was determined later by noting the times corresponding to the first and last sample taken during the period of constant concentration, as determined from accurate measurement of the countrate from the samples.

For each flow measurement, 20 samples were collected in 2.5 litre plastic bottles and the concentration of tracer in these samples was compared with the concentration of the injected solution.

\section{$5.1 .4-$ COUnTING}

The concentration of tracer in the samples cannot be measured directly but, under reproducible measurement conditions, the countrate from each sample is proportional to the concentration of tracer. To ensure that the geometry of the sample and the radiation detector is constant, a closely-fitting re-entrant sample count bottle $(\simeq 2.25$ litre $)$ is used which is filled from the sample bottle to a constant level. 


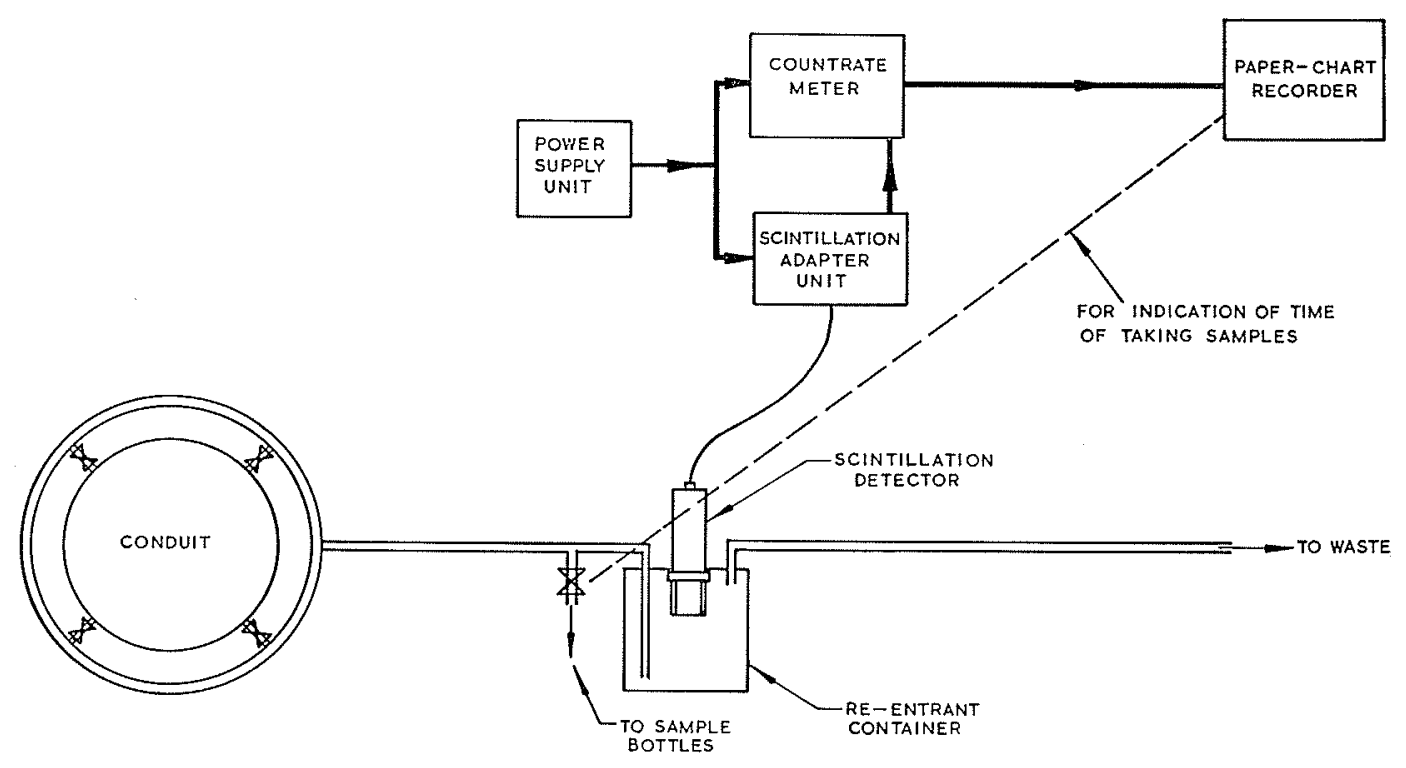

6/ Arrangement for sampling in turbine and pump direction.

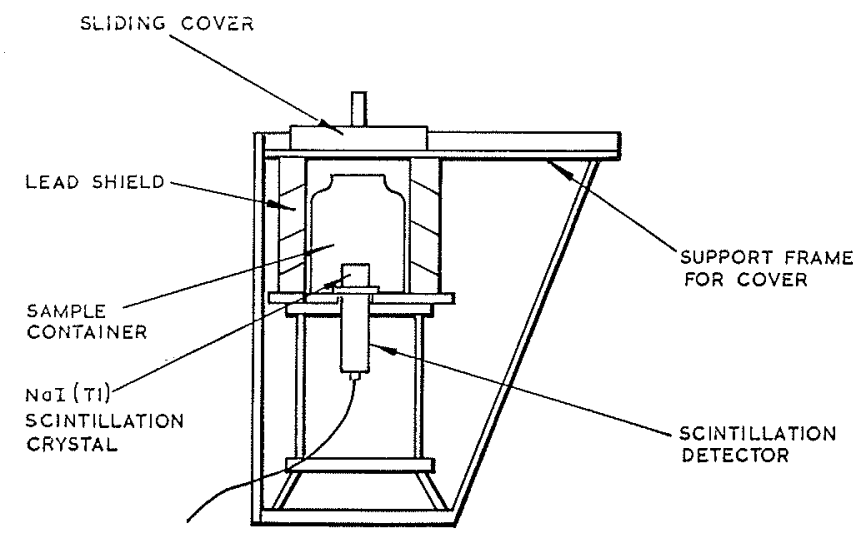

7.a/ Detector arrangement for countrate measurement.

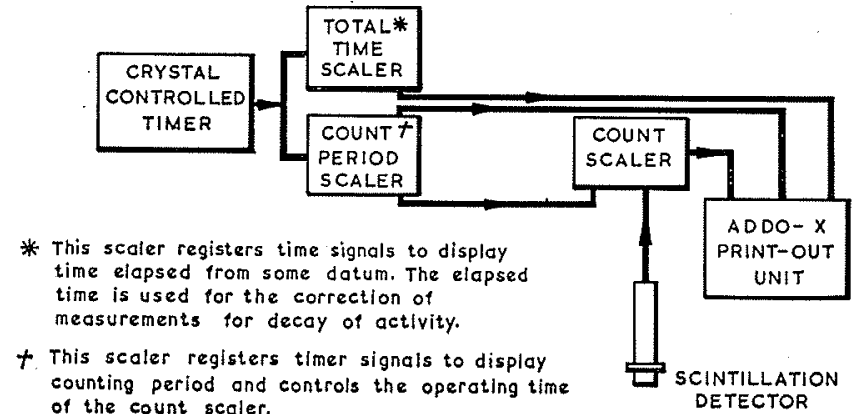

7.b/ Schematic dagram of counting equipment.

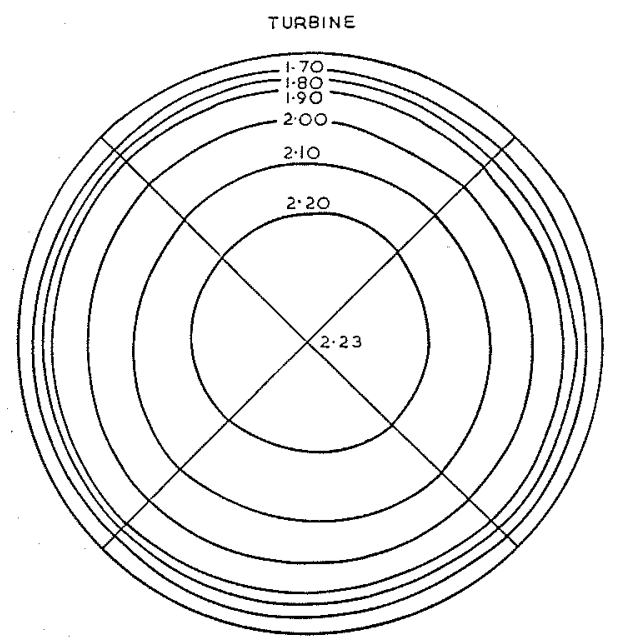

8/ Diagram of velocity distributions measured by currentmeters in turbine and pump tests.

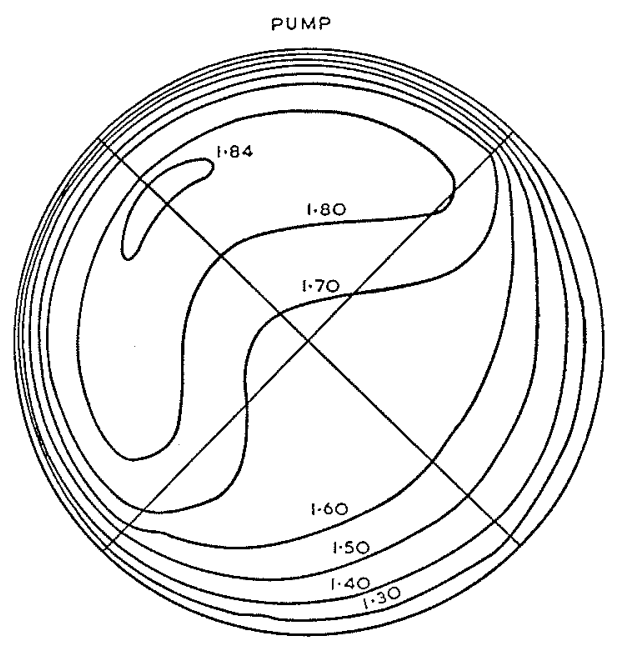


Three complete measuring equipments were used. Two were operated to establish the countrates from the samples, and one was used to measure the countrates from the diluted solutions of the injected liquid. This arrangement of counting equipment, which is shown schematically in Fig. 7, enabled two independent measurements of flowrate to be made and provided an additional check on systematic and random errors in the counting procedure. Further checks on the equipments were continually made by measuring the countrate from a small standard cobalt 60 source $(\sim 0.5 \mu \mathrm{Ci})$ and by applying statistical tests.

\section{1 .5 - Dilution}

The concentration $C_{1}$ of the injected solution is much greater than that of the samples taken from the conduit. To enable an accurate determination of the ratio of concentrations to be made, the injected solution was diluted by a factor of about $10^{6}$ so that the measured countrates from the diluted solution and samples were proportional to their respective concentrations of tracer. Since errors in making this dilution are reflected directly in the overall error of the measurement of flow, great care is needed in carrying out this procedure.

A few millilitres of the injected solution were taken from the injection pump at the beginning and end of each injection period so that sufficient dilutions [5] could be prepared to check that the injected solution was well-mixed and, at the same time, provide a precise value for the ratio of concentrations of the injected solution and samples from the conduit.

\section{2 - Mecasurement of pressure head}

The net pressure-head across the machine was measured using the same instruments and in a similar manner to that used for the current-meter tests. The instruments used were checked by measuring the pressures upstream and downstream of the machine, when the power station was not operating, and comparing the readings with measurement of the water levels. No significant errors were observed.

\section{3 - Measurement of electrical power}

The electrical power generated by the turbine and supplied to the pump was measured as described previously for the current-meters tests. The same instruments were used for each series of tests.

\section{4 - Measurements of differential pressure and guide- vane opening.}

During the tests, measurements were made of the pressure-differences obtained in the volute and draft-tube, as described for the turbine tests, using the same test equipment as that used previously. Also, measurement of the guide-vane settings were taken so that a comparison of the flowrates, as measured by the radioisotope method, could be compared with those obtained from the previous current-meter tests.

\section{6 - Test results}

A total of 23 measurements of efficiency were made on the reversible pump-turbine during the two series of tests, 17 tests when operating as a turbine and 6 when operating as a pump.

Typical velocity distributions, as measured by the current-meters in the turbine and pump tests are shown in Fig. 8 .

In the turbine tests, a symmetrical velocity distribution was obtained, but in the pump tests, because of the influence of a slight bend in the conduit upstream of the measurement section, the velocity distribution at the measuring section was distorted resulting in an increased uncertainty in the determination of mean velocity, and hence flowrate.

The values of flowrate obtained from both sets of countrate measurement equipment in the radioisotope constant-rate-injection method, and the estimated errors in measurement, are shown in Table 1 . The mean values of flowrates and their estimated errors are also given.

These values of flowrate are compared in Table 2 with the values of flowrate derived from the flow "indicators", of differential pressure and guide-vane opening as calibrated during the current-meter tests. Differences in measurement were generally less than $0.5 \%$.

The relationships of pressure differences in the volute and draft-tube of the pump-turbine obtained from the

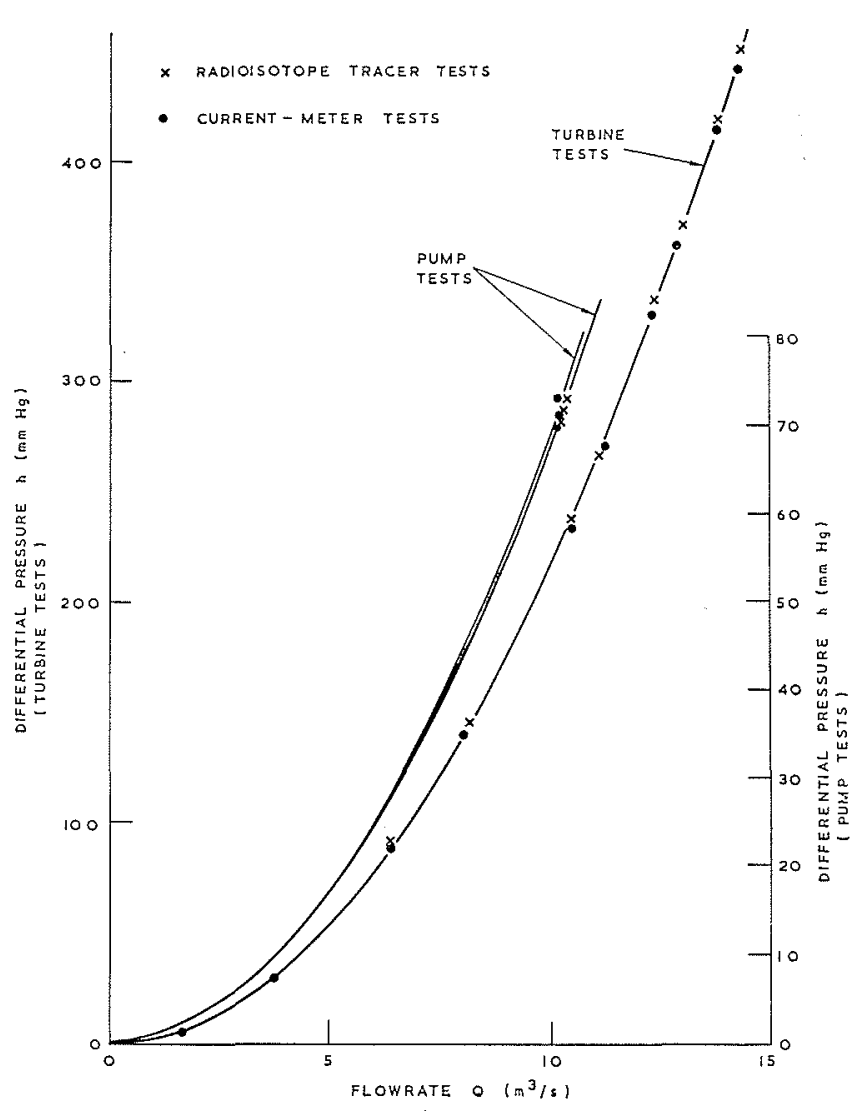

9/ Relationships of differential pressure with flowrate for turbine and pump tests. 
Table 1

Measured flowrates and estimated errors obtained with the radioisotope tracer method using two independent measuring equipments.

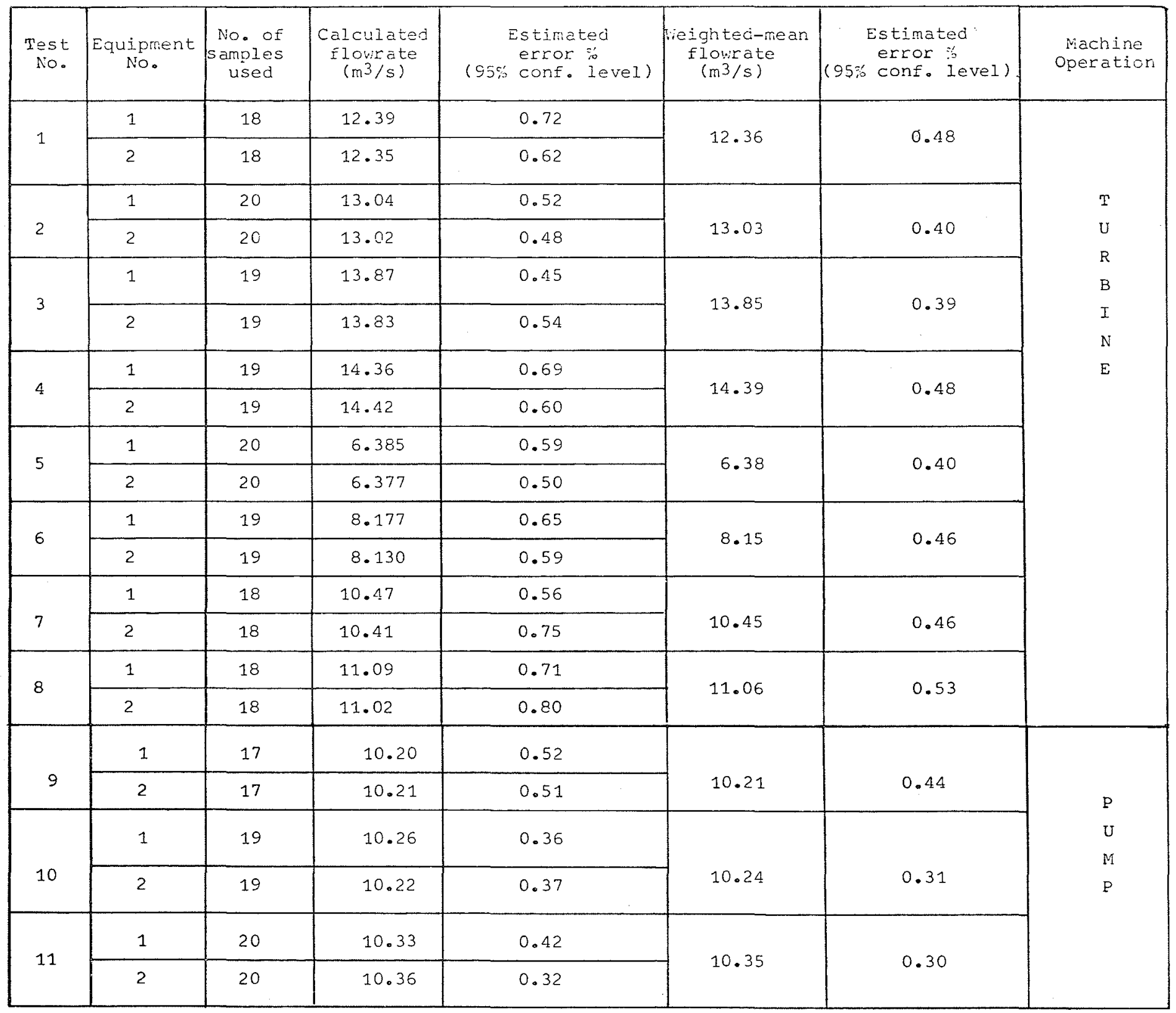


Table 2

Comparison of flowrates as measured by the radioisotope constant-rate-injection method with those derived from measurement of pressure differences and guide-vane openings (as calibrated during current-meter tests).

\begin{tabular}{|c|c|c|}
\hline $\begin{array}{c}\text { Test } \\
\text { No. }\end{array}$ & $\begin{array}{c}\text { Mean flowrate } \\
\text { as measured by the } \\
\text { radioisotope } \\
\text { constant-rate-injection } \\
\text { method } \\
\left(\mathrm{m}^{3} / \mathrm{s}\right)\end{array}$ & $\begin{array}{c}\text { Mean flourate } \\
\text { determined } \\
\text { from measurements of } \\
\text { pressure difference and } \\
\text { guide vane opening } \\
\left(\mathrm{m}^{3} / \mathrm{s}\right)\end{array}$ \\
\hline 1 & $12.36( \pm 0.48 \%)$ & 12.43 \\
2 & $13.03( \pm 0.40 \%)$ & 13.07 \\
3 & $13.85( \pm 0.39 \%)$ & 13.85 \\
4 & $14.39( \pm 0.48 \%)$ & 14.39 \\
5 & $6.38( \pm 0.40 \%)$ & 6.41 \\
6 & $8.15( \pm 0.46 \%)$ & 8.13 \\
7 & $10.45( \pm 0.46 \%)$ & 10.47 \\
8 & $11.06( \pm 0.53 \%)$ & 11.16 \\
9 & $10.21( \pm 0.44 \%)$ & 10.11 \\
10 & $10.24( \pm 0.31 \%)$ & 10.18 \\
11 & $10.35( \pm 0.30 \%)$ & 10.28 \\
\hline
\end{tabular}

turbine and pump tests are shown in Fig. 9 for the radioisotope tracer and current-meter tests.

The equations relating the pressure difference $h$ to the flowrate $Q$ for the turbine tests obtained from a regression line analysis of the test data are:
$Q=0.6808 \sqrt{h}$ (from current-meter tests) and $Q=0.6768 \sqrt{h}$ (from radioisotope tracer tests)

These relationships differ by $0.59 \%$.

The corresponding equations for the pump tests are:

$Q=1.2039 \sqrt{h}$ (from current-meter tests) and $Q=1.2130 \sqrt{h}$ (from radioisotope tracer tests)

which differ by $0.75 \%$.

The relationships of turbine efficiency against power output obtained from the two series of tests are shown in Fig. 10. The maximum values of efficiency derived from the radioisotope tracer tests were slightly higher than those derived from the current-meter tests. The differences in measured efficiences were $0.44 \%$ for the turbine and $0.66 \%$ for the pump.

These results agree within overall tolerances of $1.28 \%$ on the machine efficiency derived from the current-meter tests, as determined according to the recommendations of the International Code for the field acceptance tests of hydraulic turbines.

The objectively assessed errors on the measurement of water flowrate using the radioisotope constant-rate-injection method were between $\pm 0.30 \%$ to $0.53 \%$ (95\% confidence level). These errors, when combined with the tolerances on the measurement of electrical power $(0.8 \%)$ and pressure head $(\sim 0.1 \%)$ as given in the International Code give an overall tolerance on the determination of efficiency from the radioisotope tracer tests of between $\pm 0.86 \%$ to $\pm 0.96 \%$.

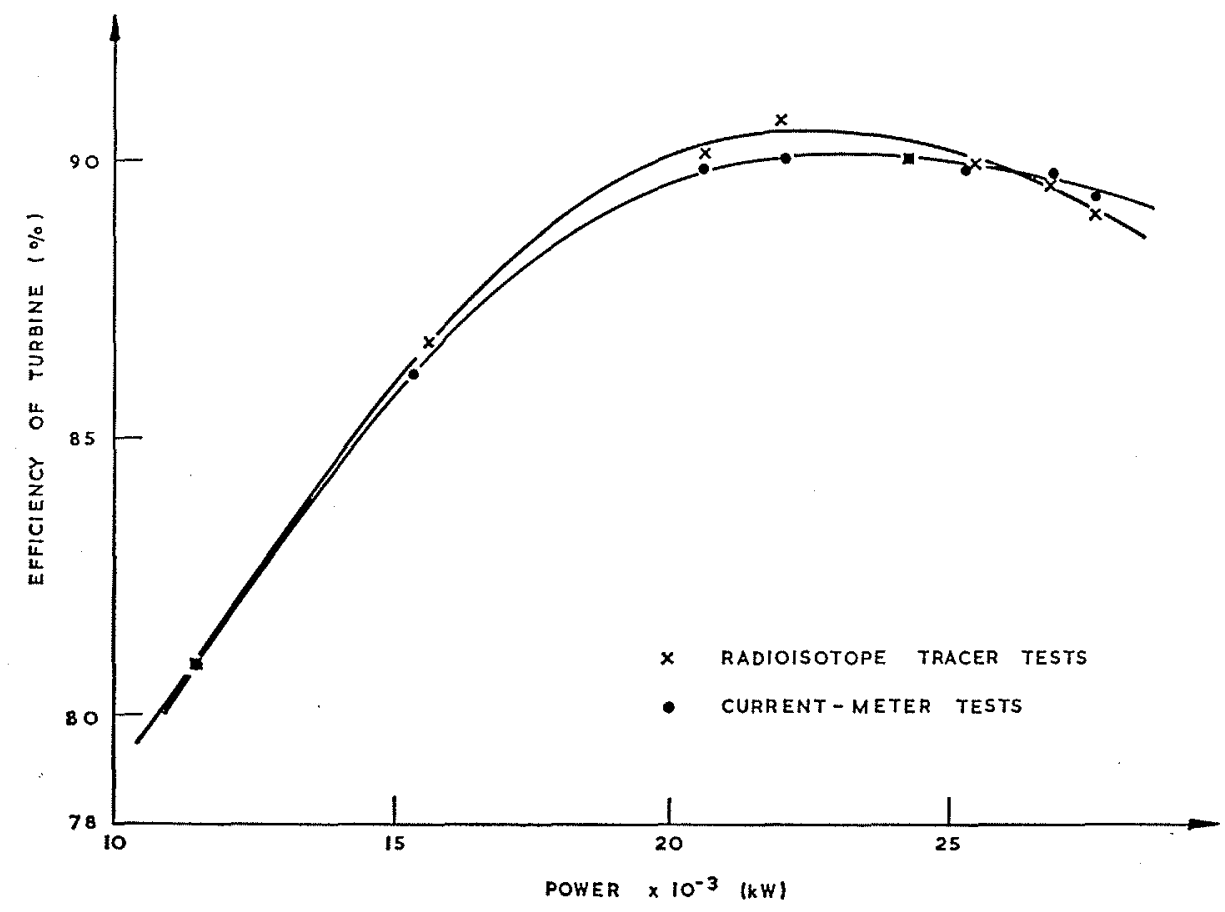

10/ Relationship of turbine efficiency with power as determined from radioisotope tracer and current-meter tests. 


\section{7 - Conclusions}

1. Efficiency tests on a reversible pump-turbine at the Central del Jares were made using current-meters and the radioisotope constant-rate-injection method to measure flowrates of water. The current-meter tests, which were made in 1970, and the radioisotope tracer tests made two years later give similar values of efficiency for the machine operating as both a pump and a turbine. Efficiencies derived from the tests differed by only $0.44 \%$ for the turbine and $0.66 \%$ for the pump.

2. Differences between the measurements of flowrate by use of the radioisotope tracer method and measurements derived from previously calibrated pressure differences differed by $0.59 \%$ for the turbine tests and $0.75 \%$ for the pump tests. The larger difference observed in the pump tests was probably due to a small error in the flowrates measured by the current-meters due to distortion of the flow caused by the slight bend upstream of the meters. Values of flowrates obtained from the radioisotope tracer method and measurements of pressure differences and guide vane openings agreed to within $\pm 0.5 \%$

3. All the measurements of efficiency of the pumpturbine agreed to within the tolerances given by the International Code for the field acceptance tests of hydraulic turbines. The overall errors in efficiency determination using the estimated errors on the measurements of flowrate by the radioisotope constant-rate-injection method and the tolerances on measurements of pressure head and electrical power recommended by the International Code were between $\pm 0.86 \%$ and $\pm 0.96 \%$ of which the largest error $( \pm 0.8 \%)$ was attributed to the measurement of electrical power.

4. The suitability of the radioisotope constant-rateinjection method for the accurate measurement of water flowrates during the on-site testing of hydraulic machines has been further demonstrated. The use of this method does not require interruption of plant operation or de-watering of the system as is required for the use of current-meters. This is of great advantage for the sitetesting of hydraulic machines.

5. This work has also shown that successful tests to measure the efficiency of hydraulic machines can be carried out by joint teams from two countries, the United Kingdom and Spain, and that a self-equipped flow measurement team from the UK is capable of participating in similar tests in Europe.

\section{8 - Acknowledgements}

Permission to publish this work was given by Saltos del Sil SA, Iberduero SA and the Director of the Atomic Energy Research Establishment at Harwell to whom the authors extend their thanks. The authors also wish to thank the staff of the Central del Jares for their co-operation during the tests, particularly Señor A. Benavent, Station Superintendent, and the Junta de Energia Nuclear, Madrid for their co-operation in supplying the isotope for the tests.

The work reported here would not have been possible without the considerable effort given by the measurement teams from Harwell and Iberduero S.A. Special thanks are therefore extended to these staff.

\section{9 - References}

[1] International code for the field acceptance tests of hydraulic turbines. International Electrotechnical Commission, publication 41, éd. 2 (1963).

[2] Winternitz (F.A. L.). - Comparison of flow measuring techniques at Kinlochleven hydro-electric station: Preliminary Tests. National Engineering Laboratory, Fluids report No. 59 (1957).

[3] Winternitz (F. A. L.). - Comparative flow measurements at Fätschbach power station. National Engineering Laboratory, Fluids report No. 92 (1960).

[4] Spencer (E. A.) and Winternitz (F. A. L.). - Comparative flow measurement tests at Finlarig power station. National Engineering Laboratory, Report No. 148 (1964).

[5] Clayton (C. G.) and Evans (G. V.) - The constant-rateinjection and velocity methods of flow measurement for testing hydraulic machines. U.K.A.E.A. Research Group, Report AERE-R 5872 (H.M.S.O., London, 1968).

[6] Aston (M.A.J.), Boyce (I.S.), Clark (W.E.), Clayton (C.G.) Evans (G. V.) and Spackman (R.). - Measurement of flow through the reversible machines at Cruachan hydro-electric pumped-storage scheme by using the radioisotope constantrate-injection method. U.K.A.E.A. Research Group, Report AERE-R 5816 (H.M.S.O., London, 1971).

[7] Clayton (C. G.) and Evans (G. V.). - Experience in the use of the radioisotope constant-rate-injection method in testing the performance of hydraulic machines. «Modern Developments in Flow Measurement 》, p. 276, C.G. Clayton, éd. (Sept. 1971); Peter Peregrinus, Stevenage (1972).

[8] Clayton (C. G.). - The use of a pump to reduce mixin longths in the dilution method of flow meaturement. U.K.A.E.A. Research Group, Report AERE-R 4623 (H.M.S.O. London, 1964). 